OPEN ACCESS

Edited by:

Zaid A. Abassi,

Technion Israel Institute of

Technology, Israel

Reviewed by:

Gerardo Gamba,

National Autonomous University of

Mexico, Mexico

Gautam Bhave,

Vanderbilt University, United States

${ }^{*}$ Correspondence:

Shih-Hua Lin

1521116@ndmctsgh.edu.tw

Specialty section:

This article was submitted to

Nephrology,

a section of the journal

Frontiers in Medicine

Received: 11 March 2021

Accepted: 11 May 2021

Published: 09 June 2021

Citation:

Sung $C-C$, Chen $M-H$, Lin $Y-C$,

Lin Y-C, Lin Y-J, Yang S-S and Lin S-H (2021) Urinary Extracellular Vesicles

for Renal Tubular Transporters Expression in Patients With Gitelman Syndrome. Front. Med. 8:679171.

doi: 10.3389/fmed.2021.679171

\section{Urinary Extracellular Vesicles for Renal Tubular Transporters Expression in Patients With Gitelman Syndrome}

\author{
Chih-Chien Sung ${ }^{1}$, Min-Hsiu Chen ${ }^{1}$, Yi-Chang Lin ${ }^{2}$, Yu-Chun Lin ${ }^{3}$, Yi-Jia Lin ${ }^{3}$, \\ Sung-Sen Yang ${ }^{1}$ and Shih-Hua Lin ${ }^{1 *}$
}

${ }^{1}$ Division of Nephrology, Department of Medicine, National Defense Medical Center, Tri-Service General Hospital, Taipei, Taiwan, ${ }^{2}$ Division of Cardiovascular Surgery, Department of Surgery, National Defense Medical Center, Tri-Service General Hospital, Taipei, Taiwan, ${ }^{3}$ Deparment of Pathology, National Defense Medical Center, Tri-Service General Hospital, Taipei, Taiwan

Background: The utility of urinary extracellular vesicles (uEVs) to faithfully represent the changes of renal tubular protein expression remains unclear. We aimed to evaluate renal tubular sodium $\left(\mathrm{Na}^{+}\right)$or potassium $\left(\mathrm{K}^{+}\right)$associated transporters expression from uEVs and kidney tissues in patients with Gitelman syndrome (GS) caused by inactivating mutations in SLC12A3.

Methods: UEVs were isolated by ultracentrifugation from 10 genetically-confirmed GS patients. Membrane transporters including $\mathrm{Na}^{+}$-hydrogen exchanger 3 (NHE3), $\mathrm{Na}^{+} / \mathrm{K}^{+} / 2 \mathrm{Cl}^{-}$cotransporter (NKCC2), NaCl cotransporter (NCC), phosphorylated NCC ( $p-\mathrm{NCC})$, epithelial $\mathrm{Na}^{+}$channel $\beta(\mathrm{ENaC} \beta)$, pendrin, renal outer medullary $\mathrm{K} 1$ channel (ROMK), and large-conductance, voltage-activated and $\mathrm{Ca}^{2+}$-sensitive $\mathrm{K}^{+}$channel (Maxi-K) were examined by immunoblotting of $\mathrm{UEV}$ s and immunofluorescence of biopsied kidney tissues. Healthy and disease (bulimic patients) controls were also enrolled.

Results: Characterization of uEVs was confirmed by nanoparticle tracking analysis, transmission electron microscopy, and immunoblotting. Compared with healthy controls, uEVs from GS patients showed NCC and p-NCC abundance were markedly attenuated but $\mathrm{NHE3}, \mathrm{ENaC} \beta$, and pendrin abundance significantly increased. ROMK and Maxi-K abundance were also significantly accentuated. Immunofluorescence of the representative kidney tissues from GS patients also demonstrated the similar findings to uEVs. uEVs from bulimic patients showed an increased abundance of NCC and p-NCC as well as NHE3, NKCC2, ENaCB, pendrin, ROMK and Maxi-K, akin to that in immunofluorescence of their kidney tissues.

Conclusion: uEVs could be a non-invasive tool to diagnose and evaluate renal tubular transporter adaptation in patients with GS and may be applied to other renal tubular diseases.

Keywords: Gitelman syndrome, renal tubular transporters, hypokalemia, renal tubular disease, urinary extracellular vesicles (exosomes) 


\section{INTRODUCTION}

Gitelman syndrome (GS) is one of the most common inherited tubulopathy with a prevalence ranging from 0.25 to $4 / 10,000$ per population. It is caused by biallelic inactivating mutations in the SLC12A3 gene encoding thiazide-sensitive sodium-chloride cotransporter (NCC) expressed in the apical membrane of distal convoluted tubules (DCT) $(1,2)$. To date, more than 450 different mutations scattered throughout SLC12A3 have been identified in GS $(1,3,4)$. Clinical characteristics include renal sodium $\left(\mathrm{Na}^{+}\right)$wasting with secondary hyperreninemia and hyperaldosteronism, renal potassium $\left(\mathrm{K}^{+}\right)$wasting with chronic hypokalemia and metabolic alkalosis, and renal magnesium wasting with hypomagnesemia, but hypocalciuria (5). The defective NCC function caused by different classes of SLC12A3 mutations leads to the reduced sodium chloride $(\mathrm{NaCl})$ reabsorption in DCT with increased luminal $\mathrm{NaCl}$ delivery to downstream collecting ducts (CD) responsible for $\mathrm{NaCl}$ reabsorption via epithelial $\mathrm{Na}^{+}$channel $(\mathrm{ENaC})$ and $\mathrm{K}^{+}$secretion via renal outer medullary $\mathrm{K} 1$ channel (ROMK) and largeconductance, voltage-activated and $\mathrm{Ca}^{2+}$-sensitive $\mathrm{K}^{+}$channel (Maxi-K). Although the expression of $\mathrm{ENaC} \beta$, ROMK and Maxi$\mathrm{K}$ in mouse GS model has been reported to be significantly increased in both immunoblotting and immunofluorescence of mouse kidney (6), the adaptive response of upstream and downstream $\mathrm{Na}^{+}$and $\mathrm{K}^{+}$associated transporters in response to renal $\mathrm{Na}^{+}$and $\mathrm{K}^{+}$wasting in GS patients remains unknown.

Urinary extracellular vesicles ( $\mathrm{uEVs}$ ) containing membrane and cytosolic proteins, mRNAs, miRNA and signaling molecules from each renal epithelial cell type may reflect the physiological state of their cells of origin $(7,8)$. The isolation of uEVs had the potential to shed much insight on the health status of the kidney and expression of urinary proteins (9-11). Knepper et al. has identified more than one thousand proteins including solute and water transporters, vacuolar $\mathrm{H}^{+}$-ATPase subunits, and disease related proteins (12). It has been also reported that the isolated $\mathrm{uEV}$ s had an increased NCC abundance in patients with primary aldosteronism $(13,14)$ and Cushing syndrome (15) as well as a rapid increase in abundance of NCC and p-NCC in healthy subjects following the mineralocorticoid administration (16). In the inherited renal tubular disorders, uEVs have been used as a non-invasive tool to detect the defect of mutated renal tubular transporter such as $\mathrm{NCC}$ and $\mathrm{Na}^{+} / \mathrm{K}^{+} / 2 \mathrm{Cl}^{-}$cotransporter (NKCC2) expression in patients with GS and Bartter syndrome, respectively $(17,18)$. Nevertheless, uEVs for other renal $\mathrm{Na}^{+}$ and $\mathrm{K}^{+}$associated transporters expression has not been also investigated in GS.

The aim of this study was to evaluate the changed expression of NCC, phosphorylated NCC (p-NCC), upstream DCT such as $\mathrm{Na}^{+}$-hydrogen exchanger 3 (NHE3), NKCC2, downstream DCT such as $\mathrm{ENaC} \beta$, pendrin, as well as $\mathrm{K}^{+}$-secreting channels such as $\mathrm{ROMK}$ and Maxi-K from $\mathrm{uEVs}$ and representative kidney tissues in patients with GS. Results to be reported indicated that a marked attenuation of NCC and p-NCC expression from uEVs could be used as a non-invasive diagnostic biomarker for GS. Both upstream NHE3 and downstream $\mathrm{ENaC} \beta$ and pendrin from uEVs were increased in response to salt-losing and an enhanced
ROMK and Maxi-K expression were associated with renal $\mathrm{K}^{+}$ wasting in GS patients. These findings from uEVs were similar to those obtained from renal biopsied tissues in GS patients.

\section{MATERIALS AND METHODS}

\section{Study Design}

The study protocol was approved by the Ethics Committee on Human Studies at Tri-Service General Hospital (TSGHIRB No.2-103-05-160 and TSGHIRB No.2-105-05-062). We prospectively collected 10 genetically confirmed GS patients. Their mutations included homozygous intronic mutation $(n=$ $2)$, compound heterozygous mutati on $(n=8)$ in the SLC12A3 gene encoding NCC (Table 1). Five healthy controls and three bulimic patients as hypokalemic disease controls were also enrolled. The diagnosis of bulimia was based on the American Psychiatric Association's Diagnostic and Statistical Manual, Fifth Edition (19). Clinical characteristics and laboratory examination were collected and determined. Renal biopsied tissues were collected from three different GS patients with definite SLC12A3 mutations (compound heterozygous mutation of intronic c1670191/p.I888_H916del, p.T60M/p.R959fs, and p.T60M/splicing c.965-1G > A+c965-977gcggacatttttgt $>$ accgaaaattttt) and one bulimic patient. All of them had long-standing, severe hypokalemia refractory to aggressive $\mathrm{K}^{+}$supplementation and significant proteinuria. Control kidney tissue was obtained from normal part of kidney in one patient with renal cell carcinoma undergoing total nephrectomy.

\section{uEVs Studies}

\section{Urine Collection and uEVs Isolation}

Secondary morning spot urine with forty milliliters with protease inhibitors were collected for uEVs isolation by ultracentrifugation-based protocol. The urine sample was centrifuged at $17,000 \times \mathrm{g}$ for $10 \mathrm{~min}$ at $37^{\circ} \mathrm{C}$. Supernatant was then ultracentrifuged at $200,000 \times \mathrm{g}$ for $2 \mathrm{~h}$ at $4^{\circ} \mathrm{C}$. The pellet was resuspended in PBS or laemmli buffer with dithiothreitol.

\section{Nanoparticle Tracking Analysis}

Nanoparticles from isolated uEVs were analyzed using the NanoSight NS300 instrument (NanoSight Ltd, Amesbury, UK). Following published method (20), all experiments were carried out at a 1:1,000 dilution, yielding particle concentrations in the region of $1 \times 10^{8}$ particles $\mathrm{ml}^{-1}$ in accordance with the manufacturer's recommendations.

\section{Transmission Electron Microscopy}

uEVs pellet was carefully fixed the with enough volume of $2.5 \%$ glutaraldehyde (G5882, Sigma-Aldrich) in $0.1 \mathrm{M}$ sodium cacodylate, $\mathrm{pH} 7.4$ and $4 \%$ paraformaldehyde mix buffer (1:1) for $1 \mathrm{~h}$ at $4^{\circ} \mathrm{C}$ and then washed with PBS. Pre-fix the sample with $1 \mathrm{ml}$ of $1 \%$ Osmium tetroxide (in $\mathrm{ddH}_{2} \mathrm{O}$ ) for $50 \mathrm{~min}$ at $4^{\circ} \mathrm{C}$ in dark. Post-fix the sample with 5\% uranyl acetate (UA) blocking overnight at $4{ }^{\circ} \mathrm{C}$. Incubate for $10 \mathrm{~min}$ with a graded $\mathrm{EtOH}$ series $(50,70,90,95,100 \%)$ and followed by EPON (Resin $20 \mathrm{ml}$, DDSA $7 \mathrm{ml}$, NMA $14 \mathrm{ml}$, DMP-30 $0.8 \mathrm{ml}$ ). The uEVs samples 
TABLE 1 | Characteristics of SLC12A3 mutation among 10 patients with Gitelman syndrome.

\begin{tabular}{|c|c|c|c|c|}
\hline Patients & Genotypes & Nucleotide change (NM_000339.3) & AA change (NP_000330.3) & Topological localization \\
\hline 1 & Compound heterozygous & c. $1924 C>T+$ c. $2548+253$ & p.R642C + Intronic & Transmembrane + C-terminal \\
\hline 2 & Homozygous & c. $1670-191 \mathrm{C}>\mathrm{T}+\mathrm{c} .1670-\mathrm{C}>\mathrm{T}$ & Intronic + Intronic & $\begin{array}{l}\text { Transmembrane + } \\
\text { Transmembrane }\end{array}$ \\
\hline 3 & Compound heterozygous & c.2875_76delAG + c.2548+253 & p.R959fs + Intronic & $\begin{array}{l}\text { C-terminal + } \\
\text { C-terminal }\end{array}$ \\
\hline 4 & Compound heterozygous & c. $2129 \mathrm{C}>\mathrm{A}+$ c.2875-76delAG & p.S710X + p.R959fs & $\begin{array}{l}\text { C-terminal + } \\
\text { C-terminal }\end{array}$ \\
\hline 5 & Compound heterozygous & c. $488 \mathrm{C}>\mathrm{T}+\mathrm{c} .2660+1 \mathrm{G}>\mathrm{A}$ & p.T163M + splicing & Transmembrane + C-terminal \\
\hline 6 & Compound heterozygous & c. $1000 \mathrm{C}>\mathrm{T}+\mathrm{c} .1326 \mathrm{C}>\mathrm{G}$ & p.R334W + p.N442K & Transmembrane + Transmembrane \\
\hline 7 & Homozygous & c. $1670-191 \mathrm{C}>\mathrm{T}+\mathrm{c} .1670-\mathrm{C}>\mathrm{T}$ & Intronic+ Intronic & $\begin{array}{l}\text { Transmembrane + } \\
\text { Transmembrane }\end{array}$ \\
\hline 8 & Compound heterozygous & c.2129C>A + c.2875_76delAG & p.S710X + p.R959fs & $\begin{array}{l}\text { C-terminal + } \\
\text { C-terminal }\end{array}$ \\
\hline 9 & Compound heterozygous & c.911C>T/c.2875_76delAG & p.T304M + p.R959fs & Transmembrane + C-terminal \\
\hline 10 & Compound heterozygous & c.2532G>A+c.805-06insTTGGCGTGGTCTCGG & $\begin{array}{l}\text { p.W844X + } \\
\text { p.T269delinsIGWSA }\end{array}$ & C-terminal + Transmembrane \\
\hline
\end{tabular}

were analyzed with a Hitachi TEM HT7700 electron microscope operated at $60 \mathrm{kV}$.

\section{Immunoblotting}

For immunoblotting, the loading volume of each uEVs sample was adjusted so that the loaded amount of creatinine was constant $(21,22)$. SDS/PAGE was carried out on an $8 \%$ polyacrylamide gel, and proteins were transferred to Immobilon ${ }^{\circledR}$-P membranes (Millipore, Amsterdam, The Netherlands). The primary antibodies were as follows: NSE (ab254088, Abcam, Cambridge, UK), TSG101 (ab125011, Abcam, Cambridge, UK), CD9 (GTX55564, Genetex, HsinChu City), AQP2 (sc-515770, Santa Cruz Biotechnology, Santa Cruz, CA), NHE3 (NHE31-A, Alpha Diagnostic Intl Inc., San Antonio, TX) (6), NKCC2 (AB2281, Millipore, Temecula, CA), NCC (AB3553, Millipore, Temecula, CA) (23), ENaC $\beta$ (ASC-019, Alomone labs, Jerusalem, Israel) (23), p-NCC (17T, in-house antibody) (23), Maxi-K (APC-021, Alomone labs, Jerusalem, Israel) (6), ROMK (APC-001, Alomone labs, Jerusalem, Israel) (6), and pendrin (ARP41739_P050, Aviva system biology, San Diego, CA). The membranes were incubated with the secondary antibody. Immunoreactive proteins were detected by the enhanced chemiluminescence method (Pierce, Rockford, IL, USA). The immunopositive bands from immunoblotting were quantified using pixel density scanning and calculated using Image $J$ and the relative band intensity was normalized to the healthy controls.

\section{Immunofluorescence of Kidney Tissue}

After paraffin removal and rehydration, the slides were heated in $1 \times$ citrate buffer (ThermoFisher) and exposed to $3 \% \mathrm{H}_{2} \mathrm{O}_{2}$ (ThermoFisher) at room temperature and then the blocking solution. After washing with PBS plus $0.1 \%$ Tween 20 (J.T. Baker), the tissue was incubated with primary antibodies at $4{ }^{\circ} \mathrm{C}$ overnight. The primary antibodies of AQP2, NHE3, NKCC2, NCC, p-NCC, ENaCB, Maxi-K, ROMK, and pendrin were used. The tissues were exposed to species-specific secondary antibodies conjugated to Alexa Fluor fluorophores (ThermoFisher). Immunofluorescence images were obtained by Zeiss LSM880 confocal microscope.

\section{Statistical Analyses}

Serum and urine biochemistry data were expressed as mean \pm standard deviation. Correlation between uEVs particles and urine creatinine were calculated by Pearson's correlation coefficient statistic in Excel. Data analyses were performed with the Prism (v5) software (GraphPad Software). Group comparisons of renal transporters from uEVs between GS patients and healthy controls were made using a two-tailed unpaired Student's $t$-test. Statistical significance was defined as $p$-values $<0.05$.

\section{RESULTS}

\section{Clinical Characteristics in GS}

As shown in Table 2, all GS patients (Male/Female $=9 / 1$, age $33.4 \pm 7.8$ years old) were normotensive with renal $\mathrm{Na}^{+}$ and $\mathrm{Cl}^{-}$wasting and secondary hyperreninemia (plasma renin activity, PRA $28.9 \pm 14.4 \mathrm{ng} / \mathrm{mL} / \mathrm{h}$ ) but normal to high plasma aldosterone concentration (PAC) $(229.4 \pm 69.6 \mathrm{pg} / \mathrm{mL})$, chronic hypokalemia $\left(\mathrm{K}^{+}, 2.34 \pm 0.45 \mathrm{mmol} / \mathrm{L}\right)$ with higher urinary $\mathrm{K}^{+}$excretion (transtubular potassium gradient, 13.46 $\pm 10.91)$, metabolic alkalosis $\left(\mathrm{HCO}^{-}, 28.7 \pm 3.9 \mathrm{mmol} / \mathrm{L}\right)$, hypomagnesemia $\left(\mathrm{Mg}^{2+} 0.63 \pm 0.07 \mathrm{mmol} / \mathrm{L}\right)$, and hypocalciuria $\left(\mathrm{Ca}^{2+} /\right.$ Creatinine $\left.0.07 \pm 0.06 \mathrm{mmol} / \mathrm{mmol}\right)$.

\section{Characterization of uEVs}

Characterization of the uEVs in healthy controls was validated by nanoparticle tracking analysis (NTA), transmission electron microscopy (TEM), and immunoblotting of uEVs makers. NTA identified size distribution of particles in the expected uEVs size range of 20-120 nm shown in Figures 1A,B. The mean particle size and concentration were $132.9 \pm 65.8 \mathrm{~nm}$ and $6.6 \times 10^{14} / \mathrm{ml}$, 
TABLE 2 | Clinical characteristics and biochemistries in patients with Gitelman syndrome.

\begin{tabular}{|c|c|c|c|c|c|c|c|c|c|c|c|c|}
\hline Patients & & 1 & 2 & 3 & 4 & 5 & 6 & 7 & 8 & 9 & 10 & Mean \pm SD \\
\hline SBP/DBP (mmHg) & & $123 / 65$ & $111 / 68$ & $120 / 80$ & $114 / 78$ & $128 / 70$ & $120 / 64$ & $126 / 64$ & $120 / 70$ & $105 / 84$ & $115 / 68$ & $116.2 \pm 7.5 / 69.7 \pm 7.4$ \\
\hline Serum & Reference & & & & & & & & & & & \\
\hline BUN (mmol/L) & $2.50-8.93$ & 5.71 & 5.36 & 7.85 & 4.64 & 6.07 & 5.36 & 7.14 & 4.64 & 4.28 & 5.71 & $5.68 \pm 1.12$ \\
\hline Creatinine $(\mu \mathrm{mol} / \mathrm{L})$ & $61.9-106.1$ & 79.6 & 88.4 & 114.9 & 530 & 106.1 & 106.1 & 88.4 & 97.2 & 70.7 & 97.2 & $90.17 .0 \pm 18.54$ \\
\hline Sodium (mmol/L) & $136-145$ & 135 & 135 & 138 & 132 & 140 & 142 & 138 & 137 & 134 & 134 & $137.1 \pm 3.1$ \\
\hline Potassium (mmol/L) & $3.5-5.1$ & 2.6 & 1.9 & 2.4 & 2.9 & 2.8 & 2.3 & 2.1 & 2.1 & 1.5 & 2.8 & $2.34 \pm 0.45$ \\
\hline Chloride (mmol/L) & $98-107$ & 97 & 100 & 98 & 94 & 97 & 99 & 97 & 98 & 96 & 96 & $97.2 \pm 1.7$ \\
\hline Total Calcium (mmol/L) & $2.15-2.55$ & 2.33 & 2.20 & 2.33 & 2.35 & 2.53 & 2.45 & 2.50 & 2.23 & 2.45 & 2.45 & $2.38 \pm 0.11$ \\
\hline Magnesium (mmol/L) & $0.7-1.05$ & 0.53 & 0.66 & 0.62 & 0.62 & 0.70 & 0.66 & 0.74 & 0.58 & 0.62 & 0.53 & $0.63 \pm 0.67$ \\
\hline Hematocrit (\%) & $38.0-47.0$ & 45.7 & 49.0 & 46.3 & 39.9 & 53.9 & 54.0 & 48.3 & 46.8 & 44.4 & 45.6 & $47.4 \pm 4.3$ \\
\hline Albumin (g/L) & $35-57$ & 43 & 37 & 43 & 48 & 47 & 46 & 43 & 38 & 46 & 45 & $44 \pm 4$ \\
\hline PRA (ng/ml/hr) & $1.31-3.95$ & 17.15 & 10.29 & 47.13 & 6.32 & 50.00 & 31.97 & 38.35 & 29.04 & 30.35 & 29.14 & $28.9 \pm 14.4$ \\
\hline PAC (pg/ml) & $70-350$ & 252 & 206 & 140 & 147 & 134 & 266 & 304 & 320 & 288 & 237 & $229.4 \pm 69.6$ \\
\hline $\mathrm{HCO}^{-}$(mmol/L) & 24 & 31.6 & 27.2 & 30.7 & 28.0 & 33.0 & 26.8 & 28.0 & 22.6 & 24.1 & 35.1 & $28.7 \pm 3.9$ \\
\hline \multicolumn{13}{|l|}{ Urine } \\
\hline Creatinine (mmol/L) & & 10.6 & 9.4 & 7.9 & 5.7 & 7.3 & 2.1 & 7.9 & 6.2 & 4.7 & 5.2 & $8.6 \pm 3.8$ \\
\hline Sodium (mmol/L) & & 172 & 53 & 58 & 66 & 64 & 46 & 96 & 32 & 42 & 199 & $82.8 \pm 57.1$ \\
\hline Potassium (mmol/L) & & 45 & 21 & 27 & 48 & 43 & 26 & 17 & 56 & 37 & 49 & $36.9 \pm 13.3$ \\
\hline Chloride (mmol/L) & & 143 & 86 & 93 & 67 & 44 & 59 & 51 & 35 & 77 & 207 & $86.2 \pm 52.4$ \\
\hline Calcium (mmol/L) & & 0.58 & 0.55 & 0.25 & 1.28 & 0.23 & 0.05 & 0.10 & 0.63 & 0.38 & 0.53 & $0.46 \pm 0.35$ \\
\hline Magnesium (mmol/L) & & 3.09 & 2.55 & 2.34 & 3.58 & 3.17 & 0.86 & 0.62 & 2.26 & 1.52 & 4.61 & $2.46 \pm 1.23$ \\
\hline TTKG & & 7.15 & 7.28 & 7.10 & 10.80 & 12.51 & 12.61 & 7.13 & 41.13 & 22.67 & 6.23 & $13.46 \pm 10.91$ \\
\hline
\end{tabular}

SBP, systolic blood pressure; DBP, diastolic blood pressure; PRA, plasma renin activity; PAC, plasma aldosterone concentration; TTKG, transtubular potassium gradient.

respectively. uEVs number was correlated strongly with urine creatinine ( $r^{2}$ for $0.81, P<0.0001$ ) shown in Figure 1C. TEM also confirmed the quality of uEVs isolated by ultracentrifugation (Figure 1D). To further validate the uEVs purification protocol, we evaluated four commonly used uEVs makers including AQP2, TSG101, NSE, and CD9 in immunoblotting shown in Figure 1E. Expression pattern of selected renal transporters including NHE3, NKCC2, NCC, p-NCC, ENaC $\beta$, pendrin, ROMK, and Maxi-K in healthy controls were shown in Figure 1F.

\section{uEVs for Renal Tubular $\mathrm{Na}^{+}$and $\mathrm{K}^{+}$ Associated Transporter Expression in GS}

Compared with healthy controls, GS patients with different biallelic mutations exhibited a markedly attenuated expression of NCC and p-NCC protein isolated from their uEVs, indicative of an impaired NCC expression and function in GS (Figures 2A,B). The expression of $\mathrm{NHE} 3, \mathrm{ENaC} \beta$, and pendrin significantly increased although NKCC2 was not significantly increased. For uEVs associated renal tubular $\mathrm{K}^{+}$associated transporter expression, GS patients had significantly increased ROMK and Maxi-K expression.

\section{Renal Tubular $\mathrm{Na}^{+}$and $\mathrm{K}^{+}$Associated Transporter Expression From Kidney Tissues in GS}

AQP2 used for a tubular maker of CD was clearly stained. Compared with control kidney tissue, the representative kidney tissues from GS patients showed obviously diminished expression in both NCC and p-NCC. The expression of NHE3, ENaC $\beta$ and pendrin was significantly increased (Figure 3). The expression of ROMK was increased and the Maxi-K unexpressed in control kidney tissue without hypokalemia was also significantly enhanced in three GS patients. Overall, these finding from immunofluorescence of kidney tissues supported the findings of the isolated $\mathrm{uEVs}$ to examine $\mathrm{Na}^{+}$and $\mathrm{K}^{+}$associated renal transporter adaptation in GS patients.

\section{Tubular Transporter Expression From uEVs and Kidney Tissue in Bulimic Patients}

Three bulimic patients (male/female $=2 / 1$, age $23.3 \pm 4.0$ years old) with normotension (systolic blood pressure $102 \pm$ $17 \mathrm{mmHg}$, diastolic blood pressure $63 \pm 5 \mathrm{mmHg}$ ) exhibited chronic hypokalemia $\left(\mathrm{K}^{+} 2.73 \pm 0.55 \mathrm{mmol} / \mathrm{L}\right)$, metabolic alkalosis $\left(\mathrm{HCO}^{-}, 46.6 \pm 11.9 \mathrm{mmol} / \mathrm{L}\right)$, with secondary hyperreninemia (PRA $4.3 \pm 1.3 \mathrm{ng} / \mathrm{mL} / \mathrm{h}$ ) but normal to high PAC (127.6 $\pm 26.7 \mathrm{pg} / \mathrm{mL})$. They all exhibited higher urinary $\mathrm{K}^{+}$excretion, high $\mathrm{Na}^{+}(120.3 \pm 80.4 \mathrm{mmol} / \mathrm{L})$ but low $\mathrm{Cl}^{-}(18.7 \pm 6.4 \mathrm{mmol} / \mathrm{L})$, alkaline urine (bicarbonaturia), indicative of recent vomiting. As shown in Figure 4A, uEV from them showed an increased abundance of NCC and p-NCC as well as NHE3, NKCC2, ENaC $\beta$, pendrin, ROMK and Maxi-K. Immunofluorescence of the kidney tissue from a representative bulimic patient also had the similar finding to those in uEVs (Figure 4B). 
A

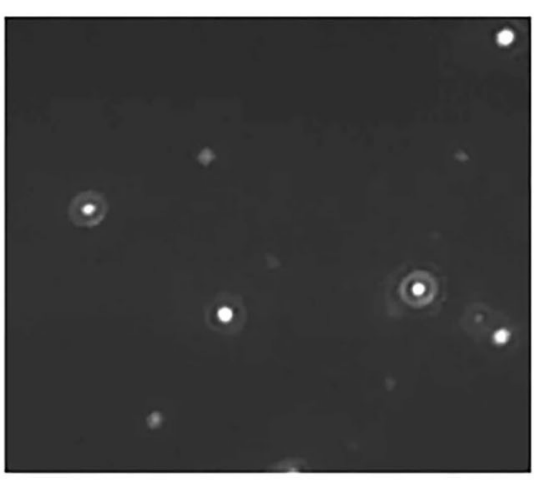

C

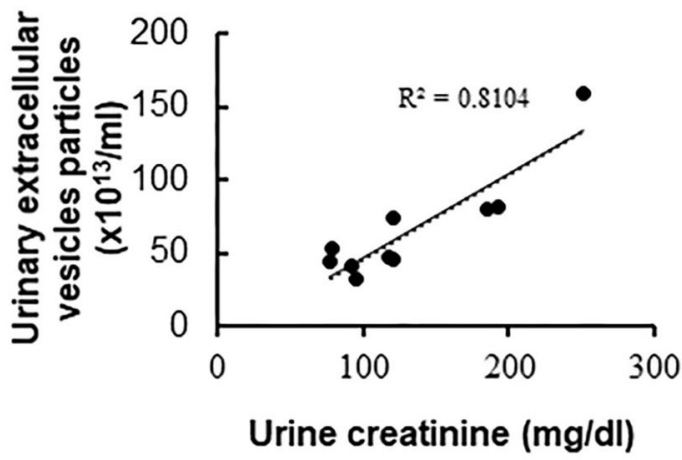

B

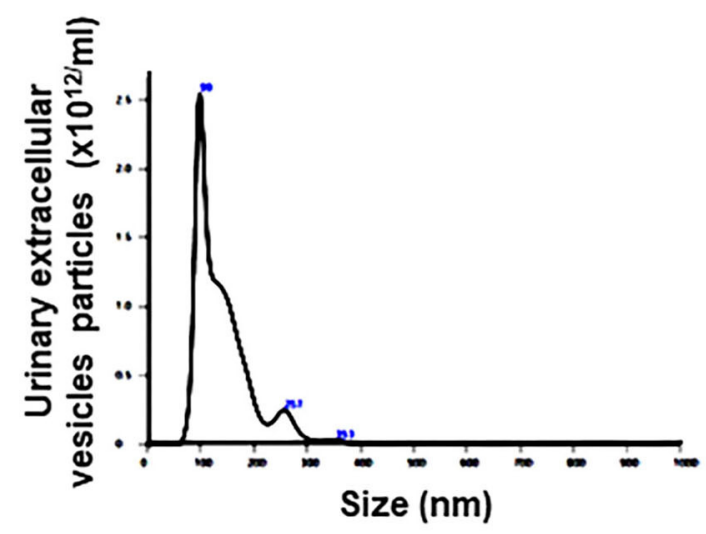

D

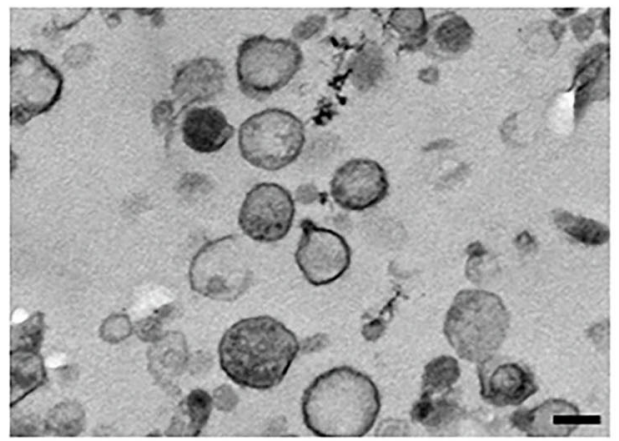

E Healthy Controls

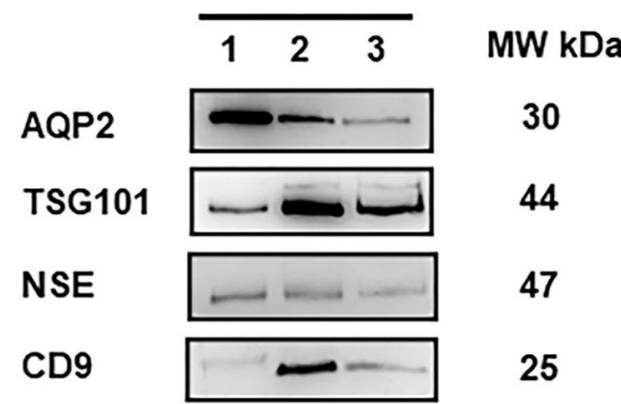

$\mathbf{F}$

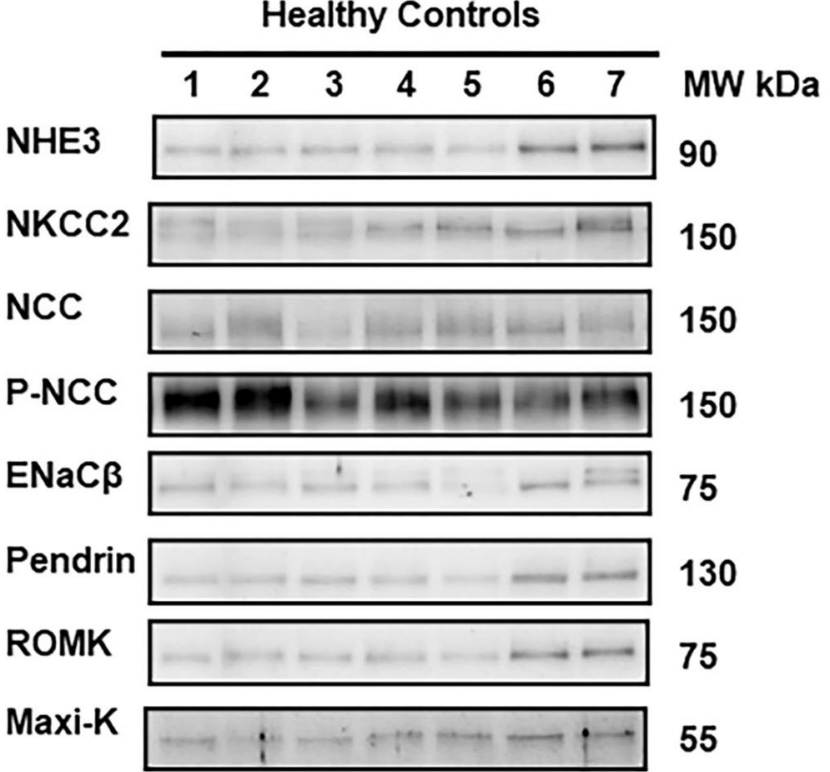

FIGURE 1 | Characterization of urinary extracellular vesicles (UEVs) from healthy controls. (A) Screen shot from 1:2,000 diluted urine sample reveals a range of particle sizes by nanoparticle tracking analysis (NTA). (B) Concentration and size distribution of uEVs (0-150 nm diameter) by NTA were shown. The concentration is expressed as number of particles per ml. (C) uEVs particles were correlated strongly with urine creatinine $\left(r^{2}\right.$ for $\left.0.81, P<0.0001\right)$. (D) Transmission electron microscopy of UEVs was shown (scale bar $100 \mathrm{~nm}$ ). (E) UEVs markers (AQP2, TSG101, NSE, and CD9) were assessed by immunoblotting. (F) Expression pattern of renal transporters including NHE3, NKCC2, NCC, p-NCC, ENaC $\beta$, pendrin, ROMK, and Maxi-K from healthy controls was similar. 
A Healthy Controls

Gitelman Syndrome

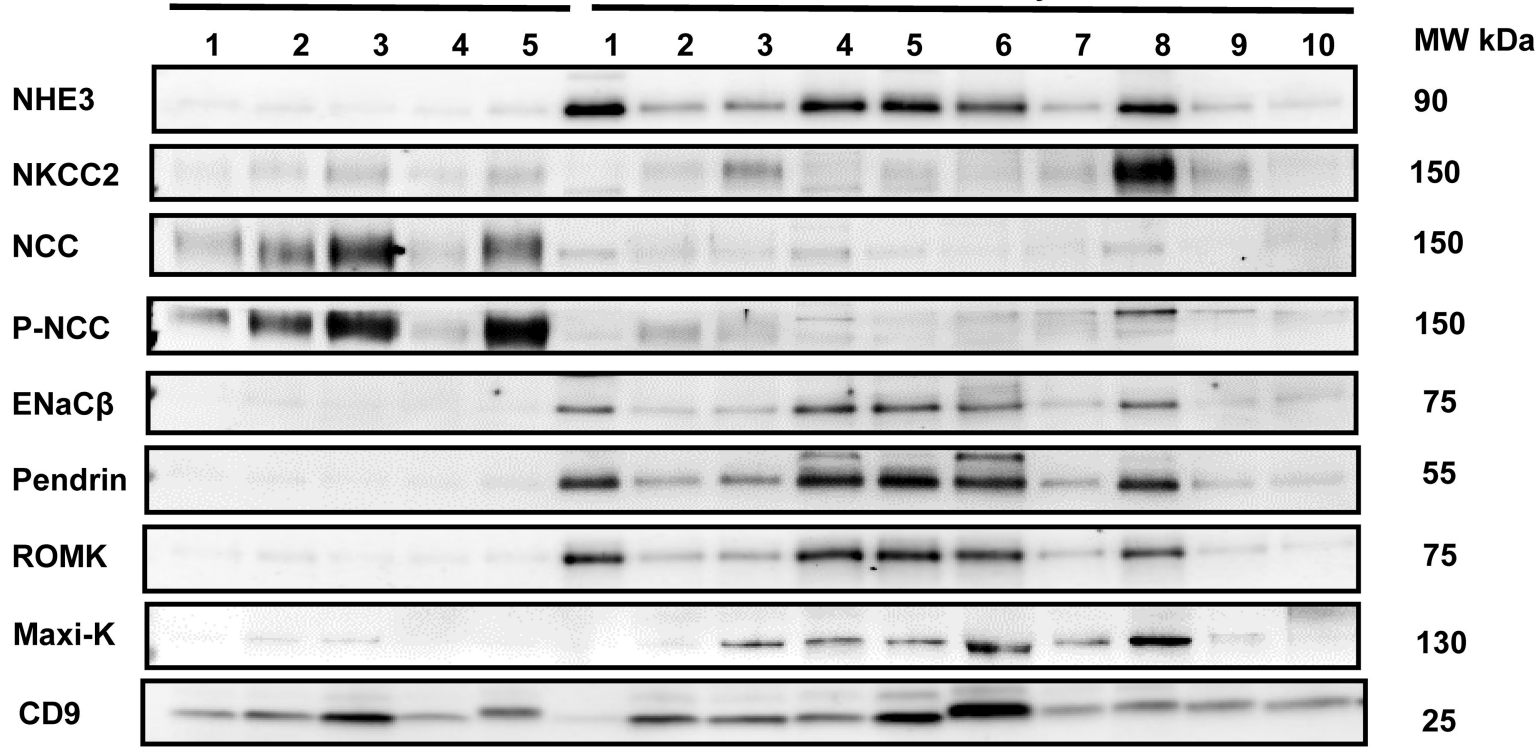

B
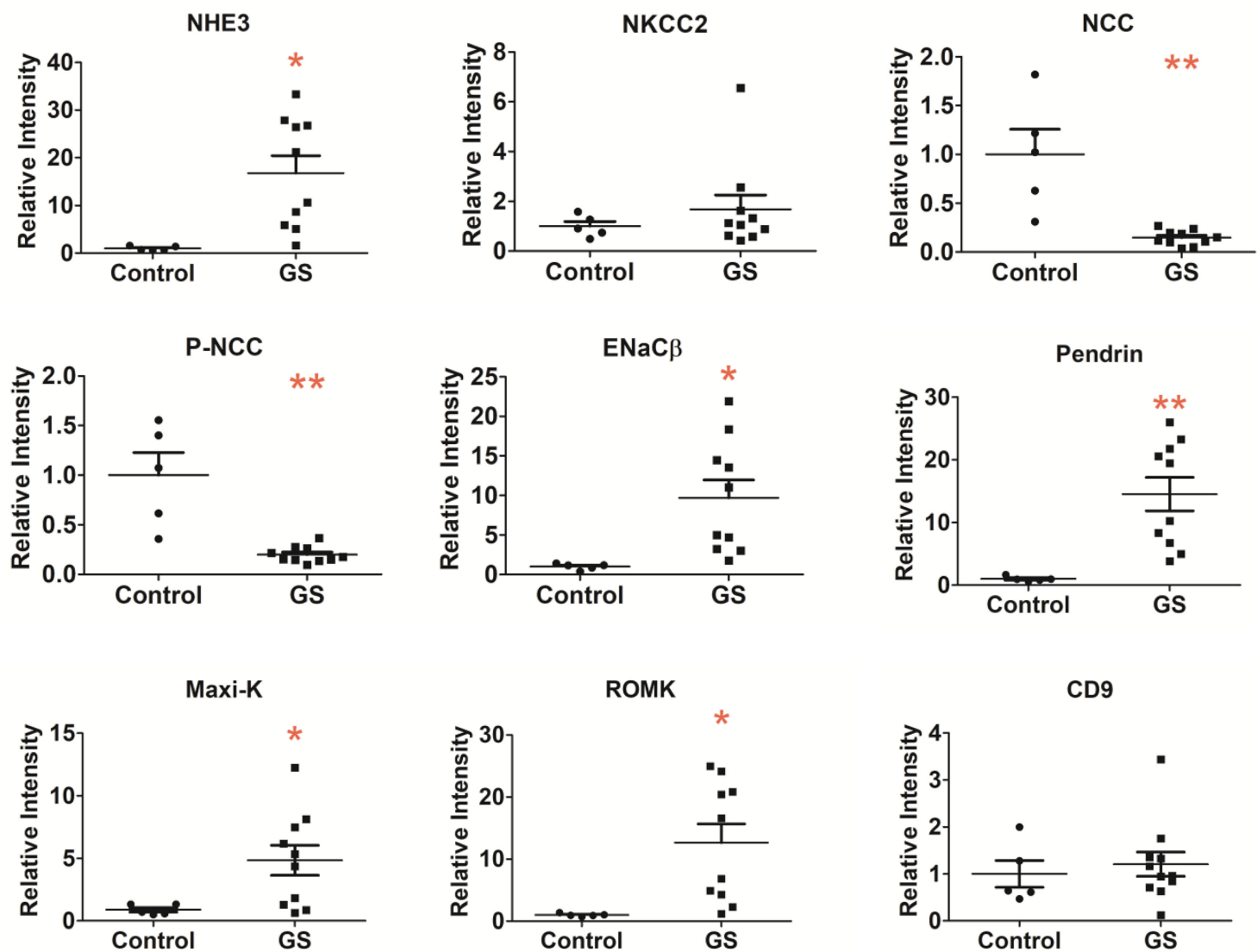

FIGURE 2 | Renal $\mathrm{Na}^{+}$and $\mathrm{K}^{+}$associated transporters expression from urinary extracellular vesicles in patients with GS $(n=10)$ compared with healthy controls. (A) Immunoblotting of renal transporters (NHE3, NKCC2, NCC, p-NCC, ENaC $\beta$, pendrin, ROMK, Maxi-K, and CD9). (B) Quantification of immunoblotting of NHE3, NKCC2, NCC, p-NCC, ENaC $\beta$, pendrin, ROMK, Maxi-K, and CD9. Error bars, standard deviation. ${ }^{*} P<0.05,{ }^{\star *} P<0.01$. 


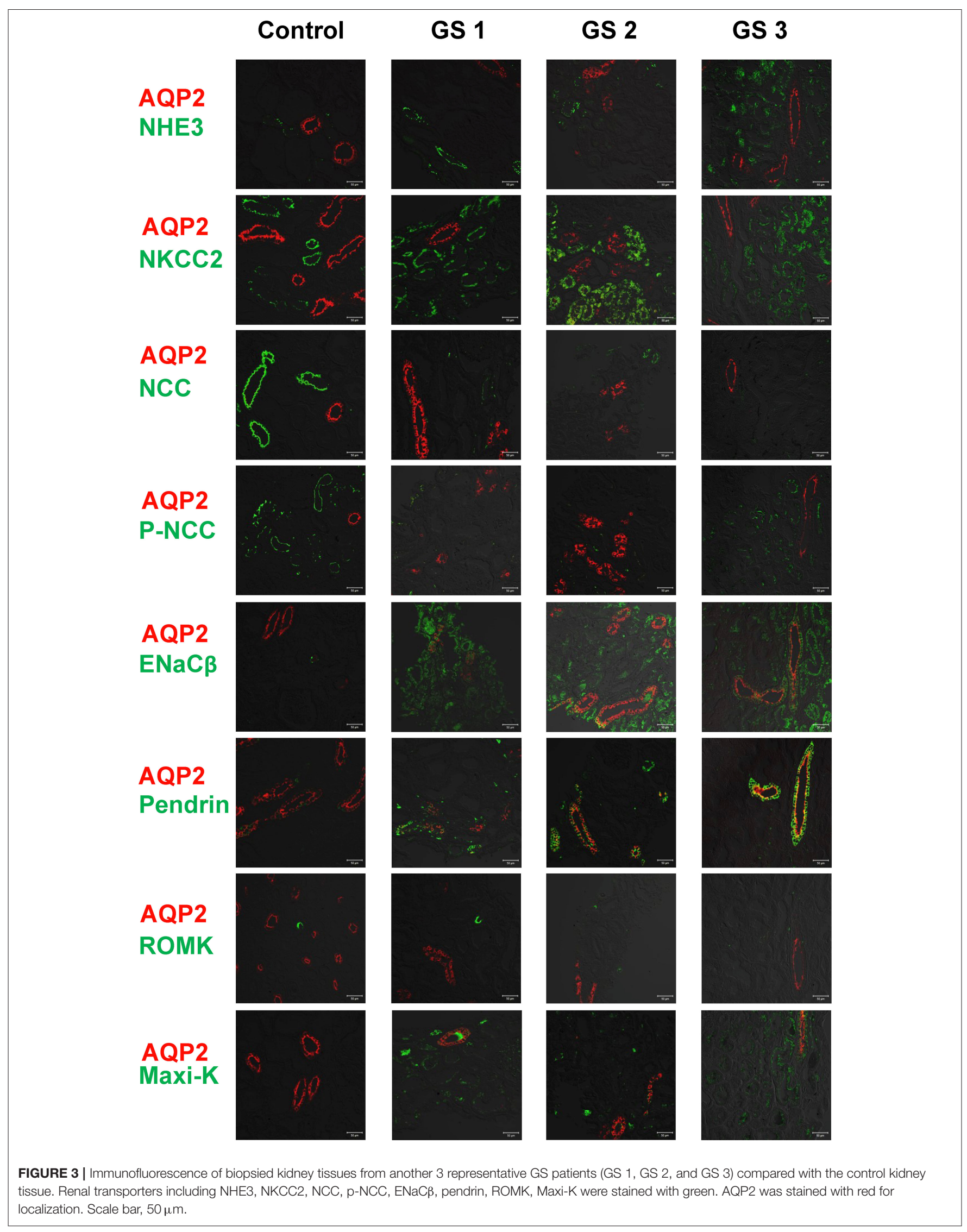


A

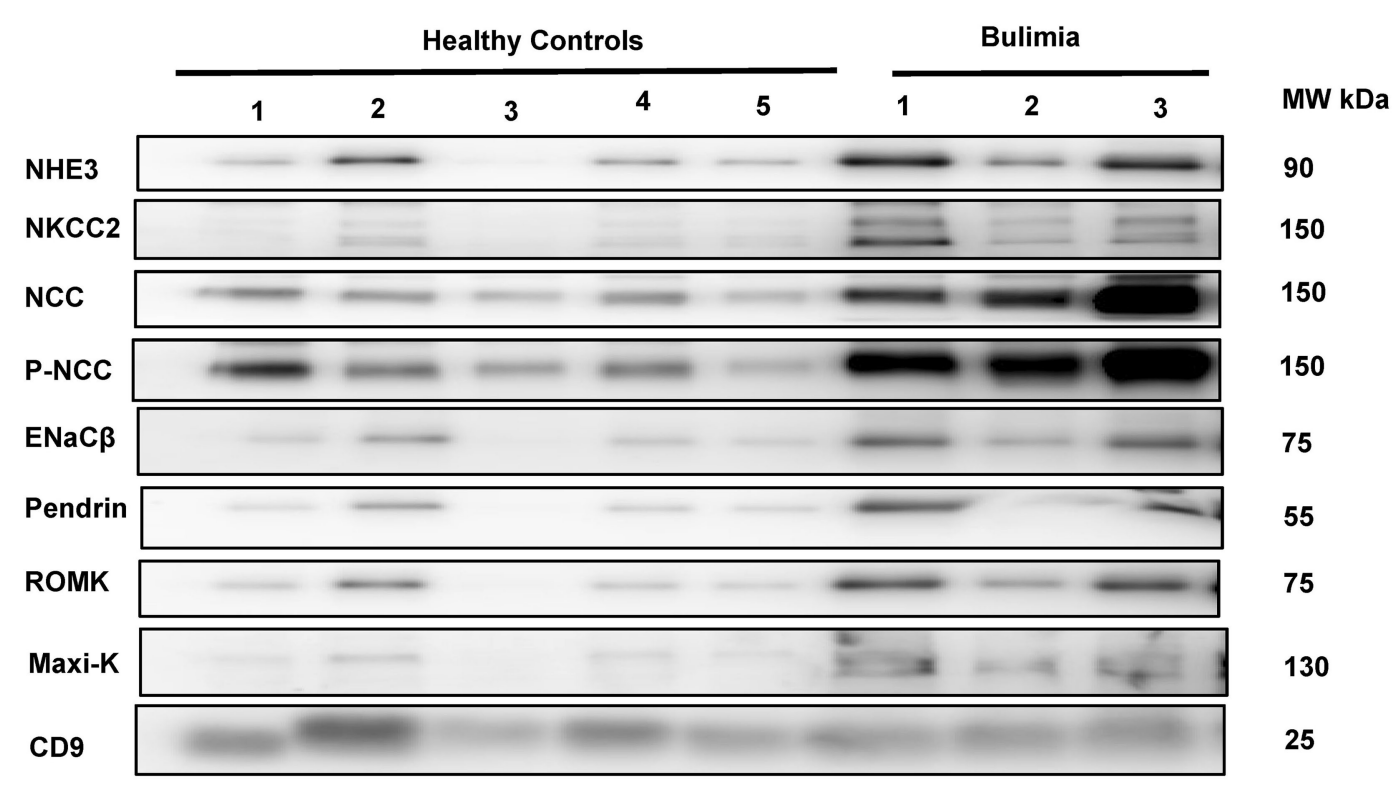

B

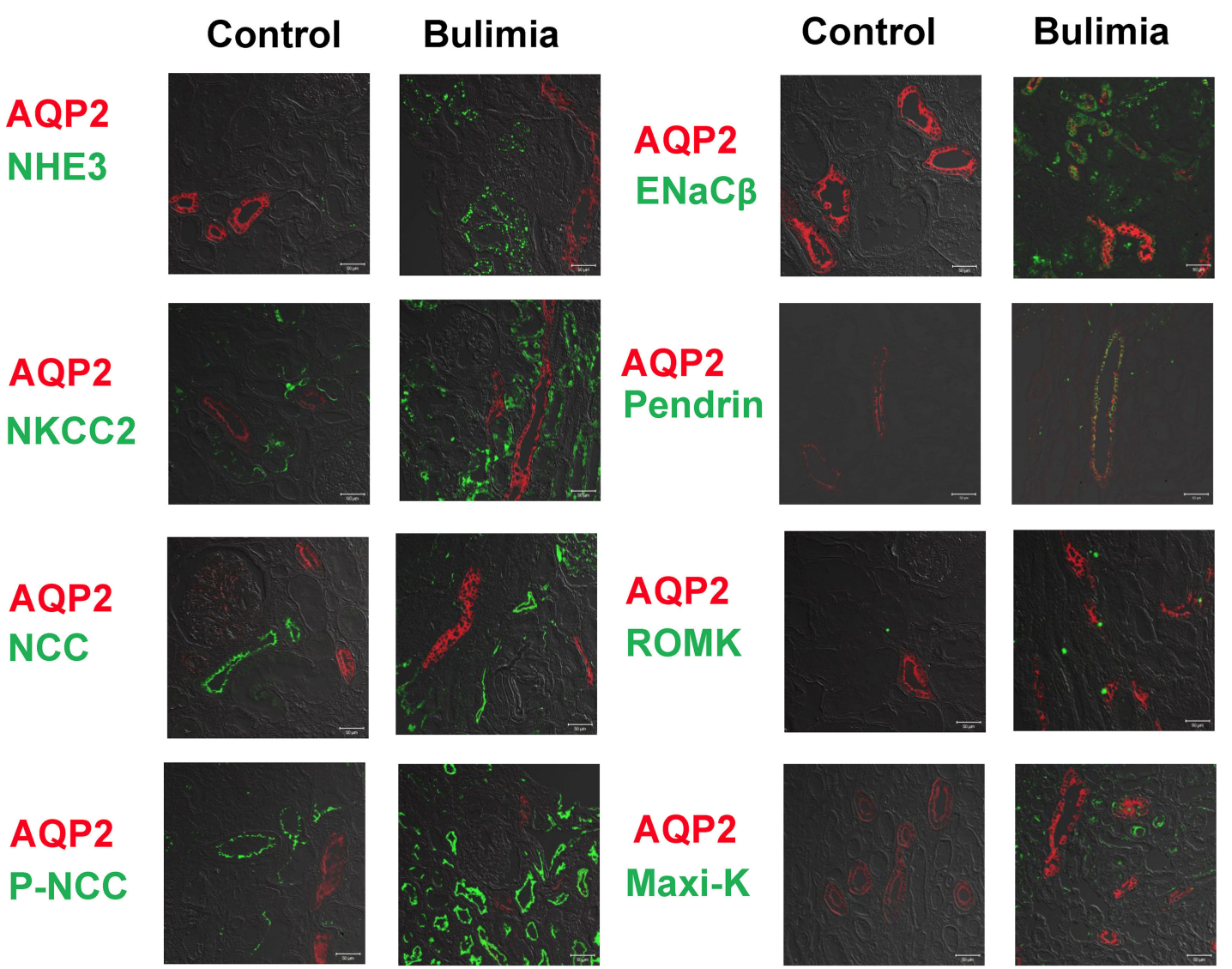

FIGURE 4 | Renal transporters expression from urinary extracellular vesicles (UEVs) and immunofluorescence of biopsied kidney tissues from bulimic patients. (A) Immunoblotting of renal transporters (NHE3, NKCC2, NCC, p-NCC, ENaC $\beta$, pendrin, ROMK, Maxi-K, and CD9) from uEVs in bulimic patients $(n=3$ ) compared with healthy control. (B) Immunofluorescence of NHE3, NKCC2, NCC, p-NCC (green, right) and ENaC $\beta$, pendrin, ROMK, Maxi-K (green, left) from one representative bulimia patient compared with the control. AQP2 was stained with red for localization. Scale bar, $50 \mu \mathrm{m}$. 


\section{DISCUSSION}

In this study, the isolated uEVs from GS patients with biallelic SLC12A3 mutations showed the markedly attenuated expression of NCC and p-NCC whereas those from non-GS bulimic patients did a significantly enhanced abundance of NCC and p-NCC. In response to renal salt loss, the expression of upstream NHE3 and downstream $\mathrm{ENaC} \beta$, and pendrin were all accentuated. The abundance of ROMK and Maxi-K expression were also augmented for renal $\mathrm{K}^{+}$wasting in GS. Immunofluorescence of the representative kidney tissues from GS and bulimic patients also demonstrated similar findings to those from uEVs. This study might be the first to assess the abundance of renal tubular $\mathrm{Na}^{+}$and $\mathrm{K}^{+}$associated transporters from uEVs and kidney tissues in GS patients.

GS caused by inactivating SLC12A3 mutations has an impaired NCC expression and/or activity as shown in both vitro and vivo studies. Although normal NCC expression with an impaired functional activity was shown in oocytes overexpressed T60M mutation at the critical NCC phosphorylation site, a markedly decreased total NCC and p-NCC protein abundance was evident in NccT58M/T58M GS knock-in mice and in the urine of human GS with homozygous T60M mutations (23). In addition, the reduced or abolished NCC abundance on the apical membrane of DCT from the human kidney tissues in GS patients with $S L C 12 A 3$ mutations were also demonstrated $(24,25)$. These findings supported the notion that the reduced expression of NCC was a biomarker for GS despite different mechanisms involved in the impaired NCC protein synthesis (24, 26), and sorting or trafficking defect of NCC (27). Accordingly, it is important to find a non-invasive method to faithfully represent NCC abundance in GS. Previous studies using uEVs to measure the mutated NCC by immunoblotting and enzymelinked immunosorbent assays (ELISAs) in GS patients only showed the decreased NCC abundance $(17,18)$. In this study, the isolated uEVs from GS patients revealed that both NCC and pNCC abundance were markedly diminished, also confirmed by the human kidney tissue of genetically-confirmed GS patients.

It is of great interest to understand and localize the tubular adaptation in the inherited renal tubular disorders. The traditional methods were the preparation of whole kidney sections for immunostaining and immunoblotting or biotinylating the rat or mice kidney tissues in situ under various chronic conditions in animal models. Tubular adaptation to renal $\mathrm{Na}^{+}$loss has been evaluated in the distal tubules in experimental models of GS but not human GS. Knepper et al. has used the LC-MS/MS to profile the proteome of human uEVs and suggested that uEVs analysis be a potential approach to discover adaptation in renal transporters (12). Using uEVs analysis in GS, we found that the abundance of upstream NHE3 in the proximal tubules (PT) necessary for bicarbonate reabsorption, salt and fluid homeostasis was significantly increased (28-30). Renal NHE3 abundance was markedly increased in $\mathrm{K}^{+}$-depleted rats (31), indicating that NHE3 expression can be also regulated by the hypokalemia independent of volume depletion. Similarly, downstream $\mathrm{ENaC} \beta$ in the principal cells of $\mathrm{CD}$ for tubular salt reabsorption was enhanced $(32,33)$. Of note, pendrin as a
$\mathrm{Cl}^{-} / \mathrm{HCO}^{-}$exchanger expressed in the apical region of distal tubules and involved in the tubular $\mathrm{Cl}^{-}$absorption and $\mathrm{HCO}^{-}$ secretion was augmented (34). Activation of pendrin-mediated $\mathrm{Cl}^{-}$absorption has also been reported in NCC KO mice (35). Although pendrin expression has been examined in many rodent treatment models such as NCC KO mice, an aldosterone infusion or the administration of $\mathrm{NaHCO}_{3}$ to regulate acid-base and salt regulation, our study suggested the increased pendrin expression from uEVs and biopsied kidney tissues be responsive to renal salt wasting and also chronic metabolic alkalosis in GS patients.

$\mathrm{K}^{+}$excretion in distal nephron is driven by either voltagedependent ROMK and/or flow dependent Maxi-K (36). ROMK is an inwardly rectifying $\mathrm{K}^{+}$channel (37) traditionally responsible for the main renal $\mathrm{K}^{+}$secretory channel, dependent on $\mathrm{Na}^{+}$delivery and driven by electrogenic ENaC-mediated $\mathrm{Na}^{+}$ reabsorption (38-40). Maxi-K is flow-stimulated $\mathrm{K}^{+}$secretion and activated by an increase in intracellular calcium and membrane depolarization $(41,42)$. Defective $\mathrm{NaCl}$ absorption in DCT leads to the increased flow rate to downstream connecting tubules (CNT) and CD to naturally stimulate both ROMK and Maxi-K. In animal model of GS (Ser707X knockin mice), an enhanced expression of both ROMK and Maxi-K has been clearly shown (6). Our uEVs for the expression of both ROMK and Maxi-K abundance were significantly increased in GS patients, akin to the findings of their representative immunofluorescence of kidney tissues. Of note, the abundance of Maxi-K was extremely low in both uEVs and biopsied kidney in controls but higher in GS patients, indicating that Maxi-K expression was more augmented at the high urinary flow rate.

The above-mentioned findings with an increased protein expression related to $\mathrm{Na}^{+}$reabsorption, $\mathrm{K}^{+}$secretion and regulation of acid/base balance at distal nephron from the uEVs in our GS patients with diminished NCC expression consisted with current idea that distal tubules including CD are highly plastic. Tubular plasticity for adaptation is defined as structural remodeling of renal tubules via cell proliferation (hyperplasia) and cell growth (hypertrophy) $(43,44)$. In NCCdeficient mice, early DCT showed a remarkable atrophy but CNT exhibited a marked epithelial hypertrophy accompanied by an increased apical abundance of ENaC (45). In SPAK KO mice featuring GS-like phenotypes, a distal nephron remodeling process of the CNT/CD developed to produce an increase in the numbers of principle cells and $\beta$-intercalated cells (46). These two mice models with deficient NCC clearly demonstrated the markedly attenuated DCT along with the distinctly hypertrophic and/or hyperplastic CNT/CD. Our uEVs results in GS patients were similar to those from NCC deficient animal studies, also supporting the notion of nephron plasticity with compensatory increase in the CNT/CD size.

Bulimic patients, also called pseudo-GS syndrome $(47,48)$, exhibiting similar laboratory and clinical features to GS, were also evaluated for disease controls. In contrast to GS patients, uEVs from bulimic patients showed a markedly enhanced abundance of NCC and p-NCC. The increased NCC and p-NCC abundance may be secondary response to volume depletion and $\mathrm{K}^{+}$deficiency per se. In rat model of $\mathrm{K}^{+}$deficiency, enhanced abundance NCC and p-NCC has been clearly shown (49), 
closely linked to increased WNK body formation and activation of SPAK/OSR1 (50). Similarly, uEVs for upstream NHE3 and NKCC2 along with downstream $\mathrm{ENaC} \beta$ and pendrin expression were also increased in response to salt-losing and metabolic alkalosis. Of interest, only the slightly increased ROMK and Maxi-K abundance from the isolated uEVs and biopsied kidney tissues may be associated with the interaction of bicarbonaturia to stimulate them as well as the enhanced NCC and chronic hypokalemia to suppress them.

Recently, uEVs has been emerged as a promising liquid biopsy biomarker in kidney disease research. Several novel biomarkers from uEVs including proteins, miRNA or noncoding RNA have been discovered in acute kidney injury $(51,52)$, chronic kidney disease $(53,54)$, diabetic nephropathy (55), focal segmental glomerulosclerosis (56), and lupus nephritis (57). In addition to GS and Bartter syndrome, uEVs is also utilized in some renal tubular disorders such as nephrogenic diabetes insipidus, and familial hyperkalemic hypertension due to KLHL3 mutation (58). Accordingly, these evidence demonstrated the relevance of uEVs in understanding the pathophysiology of kidney diseases and the discovery of potential therapeutic targets. Our study provided a feasible way to analyze the differential expression proteins in renal tubular disorders and may be also applied to other non-tubular disorder such as cisplatin or drug induced tubulopathy.

There were some limitations of this study. First, the sample size of GS patients was still small due to the restricted loading wells of SDS/PAGE for immunoblotting. Second, other relevant transporters along the renal tubules such as TRPV5 and TRPM6 were not examined because of limited uEVs proteins isolated from ultracentrifugation. Third, the localization of these transporters in renal tubules could not be identified using uEVs. Finally, the specificity and sensitivity of the antibodies used for this study might affect expression of renal transporters between immunoblotting and immunofluorescence (for example NKCC2). Using the detergent for immunoblotting is another approach to enhance intracellular epitope recognition in uEVs (22).

In conclusion, uEV s could be used as non-invasive diagnostic tool to evaluate the renal tubular $\mathrm{Na}^{+}$or $\mathrm{K}^{+}$associated

\section{REFERENCES}

1. Blanchard A, Bockenhauer D, Bolignano D, Calò LA, Cosyns E, Devuyst O, et al. Gitelman syndrome: consensus and guidance from a Kidney Disease: Improving Global Outcomes (KDIGO) Controversies Conference. Kidney Int. (2017) 91:24-33. doi: 10.1016/j.kint.2016.09.046

2. Simon DB, Nelson-Williams C, Bia MJ, Ellison D, Karet FE, Molina AM, et al. Gitelman's variant of Bartter's syndrome, inherited hypokalaemic alkalosis, is caused by mutations in the thiazide-sensitive $\mathrm{Na}-\mathrm{Cl}$ cotransporter. Nat Genet. (1996) 12:24-30. doi: 10.1038/ng0196-24

3. Lo Y-F, Nozu K, Iijima K, Morishita T, Huang C-C, Yang S-S, et al. Recurrent deep intronic mutations in the SLC12A3 gene responsible for Gitelman's syndrome. Clin J Am Soc Nephrol. (2011) 6:630-9. doi: 10.2215/CJN.06730810

4. Vargas-Poussou R, Dahan K, Kahila D, Venisse A, Riveira-Munoz E, Debaix $\mathrm{H}$, et al. Spectrum of mutations in Gitelman syndrome. J Am Soc Nephrol. (2011) 22:693-703. doi: 10.1681/ASN.2010090907 transporters expression in GS patients. High-throughput proteomic studies from uEVs in GS patients will be anticipated in the further investigation.

\section{DATA AVAILABILITY STATEMENT}

The original contributions presented in the study are included in the article/supplementary material, further inquiries can be directed to the corresponding author/s.

\section{ETHICS STATEMENT}

The studies involving human participants were reviewed and approved by Institutional Review Board of the Tri-Service General Hospital of Taiwan (TSGHIRB No.2-103-05-160 and TSGHIRB No.2-105-05-062). The patients/participants provided their written informed consent to participate in this study.

\section{AUTHOR CONTRIBUTIONS}

C-CS, M-HC, and S-HL substantially contributed to study conception and design, acquisition of data, and analysis and interpretation of data. Y-ChaL, Y-ChuL, Y-JL, and S-SY substantially contributed to acquisition of data, and analysis and interpretation of data. All the authors revised the paper and approved the final version of the article to be published.

\section{FUNDING}

This research was supported by grants from the Research Fund of the Ministry of Science and Technology (MOST) of Taiwan (MOST 104-2314-B-016-021-MY2 and MOST 106-2314B-016-033-MY3) and the Research Fund of the Tri-Service General Hospital (TSGH-C107-007-S04, TSGH-C108-007-S04, and TSGH-C108-027).

\section{ACKNOWLEDGMENTS}

The authors acknowledge technical services provided by Instrument Center of National Defense Medical Center.
5. Tseng MH, Yang SS, Hsu YJ, Fang YW, Wu CJ, Tsai JD, et al. Genotype, phenotype, and follow-up in Taiwanese patients with salt-losing tubulopathy associated with SLC12A3 mutation. J Clin Endocrinol Metab. (2012) 97:E1478-82. doi: 10.1210/jc.2012-1707

6. Yang SS, Lo YF, Yu IS, Lin SW, Chang TH, Hsu YJ, et al. Generation and analysis of the thiazide-sensitive $\mathrm{Na}+-\mathrm{Cl}-$ cotransporter (Ncc/Slc12a3) Ser707X knockin mouse as a model of Gitelman syndrome. Hum Mutat. (2010) 31:1304-15. doi: 10.1002/humu.21364

7. van Balkom BW, Pisitkun T, Verhaar MC, Knepper MA. Exosomes and the kidney: prospects for diagnosis and therapy of renal diseases. Kidney Int. (2011) 80:1138-45. doi: 10.1038/ki.2011.292

8. Pisitkun T, Shen RF, Knepper MA. Identification and proteomic profiling of exosomes in human urine. Proc Natl Acad Sci USA. (2004) 101:13368-73. doi: 10.1073/pnas.0403453101

9. Gonzales P, Pisitkun T, Knepper MA. Urinary exosomes: is there a future? Nephrol Dial Transplant. (2008) 23:1799-801. doi: 10.1093/ndt/gfn058 
10. Knepper MA, Pisitkun T. Exosomes in urine: who would have thought? Kidney Int. (2007) 72:1043-5. doi: 10.1038/sj.ki.5002510

11. Bonifacino JS, Traub LM. Signals for sorting of transmembrane proteins to endosomes and lysosomes. Annu Rev Biochem. (2003) 72:395-447. doi: 10.1146/annurev.biochem.72.121801.161800

12. Gonzales PA, Pisitkun T, Hoffert JD, Tchapyjnikov D, Star RA, Kleta R, et al. Large-scale proteomics and phosphoproteomics of urinary exosomes. J Am Soc Nephrol. (2009) 20:363-79. doi: 10.1681/ASN.2008040406

13. van der Lubbe N, Jansen PM, Salih M, Fenton RA, van den Meiracker AH, Danser AH, et al. The phosphorylated sodium chloride cotransporter in urinary exosomes is superior to prostasin as a marker for aldosteronism. Hypertension. (2012) 60:741-8. doi: 10.1161/HYPERTENSIONAHA.112.198135

14. Salih M, Fenton RA, Zietse R, Hoorn EJ. Urinary extracellular vesicles as markers to assess kidney sodium transport. Curr Opin Nephrol Hypertens. (2016) 25:67-72. doi: 10.1097/MNH.0000000000000192

15. Salih M, Bovée DM, van der Lubbe N, Danser AHJ, Zietse R, Feelders RA, et al. Increased urinary extracellular vesicle sodium transporters in Cushing syndrome with hypertension. J Clin Endocrinol Metab. (2018) 103:2583-91. doi: 10.1210/jc.2018-00065

16. Wolley MJ, Wu A, Xu S, Gordon RD, Fenton RA, Stowasser M. In primary aldosteronism, mineralocorticoids influence exosomal sodiumchloride cotransporter abundance. J Am Soc Nephrol. (2017) 28:56-63. doi: 10.1681/ASN.2015111221

17. Corbetta S, Raimondo F, Tedeschi S, Syrèn ML, Rebora P, Savoia A, et al. Urinary exosomes in the diagnosis of Gitelman and Bartter syndromes. Nephrol Dial Transplant. (2015) 30:621-30. doi: 10.1093/ndt/gfu362

18. Isobe K, Mori T, Asano T, Kawaguchi H, Nonoyama S, Kumagai N, et al. Development of enzyme-linked immunosorbent assays for urinary thiazidesensitive $\mathrm{Na}-\mathrm{Cl}$ cotransporter measurement. Am J Physiol Renal Physiol. (2013) 305:F1374-81. doi: 10.1152/ajprenal.00208.2013

19. Vahia VN. Diagnostic and statistical manual of mental disorders 5: a quick glance. Indian J Psychiatry. (2013) 55:220-3. doi: 10.4103/0019-5545.117131

20. Sokolova V, Ludwig AK, Hornung S, Rotan O, Horn PA, Epple M, et al. Characterisation of exosomes derived from human cells by nanoparticle tracking analysis and scanning electron microscopy. Colloids Surf B Biointerfaces. (2011) 87:146-50. doi: 10.1016/j.colsurfb.2011.05.013

21. Abdeen A, Sonoda H, Oshikawa S, Hoshino Y, Kondo H, Ikeda M. Acetazolamide enhances the release of urinary exosomal aquaporin-1. Nephrol Dial Transplant. (2016) 31:1623-32. doi: 10.1093/ndt/gfw033

22. Blijdorp CJ, Tutakhel OAZ, Hartjes TA, van den Bosch TPP, van Heugten $\mathrm{MH}$, Rigalli JP, et al. Comparing approaches to normalize, quantify, and characterize urinary extracellular vesicles. J Am Soc Nephrol. (2021) 32:121026. doi: 10.1681/ASN.2020081142

23. Yang SS, Fang YW, Tseng MH, Chu PY, Yu IS, Wu HC, et al. Phosphorylation regulates NCC stability and transporter activity in vivo. J Am Soc Nephrol. (2013) 24:1587-97. doi: 10.1681/ASN.2012070742

24. Joo KW, Lee JW, Jang HR, Heo NJ, Jeon US, Oh YK, et al. Reduced urinary excretion of thiazide-sensitive $\mathrm{Na}-\mathrm{Cl}$ cotransporter in Gitelman syndrome: preliminary data. Am J Kidney Dis. (2007) 50:765-73. doi: 10.1053/j.ajkd.2007.07.022

25. Jang HR, Lee JW, Oh YK, Na KY, Joo KW, Jeon US, et al. From bench to bedside: diagnosis of Gitelman's syndrome - defect of sodiumchloride cotransporter in renal tissue. Kidney Int. (2006) 70:813-7. doi: 10.1038/sj.ki.5001694

26. Syrén ML, Tedeschi S, Cesareo L, Bellantuono R, Colussi G, Procaccio M, et al. Identification of fifteen novel mutations in the SLC12A3 gene encoding the Na-Cl Co-transporter in Italian patients with Gitelman syndrome. Hum Mutat. (2002) 20:78. doi: 10.1002/humu.9045

27. De Jong JC, Van Der Vliet WA, Van Den Heuvel LP, Willems PH, Knoers NV, Bindels RJ. Functional expression of mutations in the human $\mathrm{NaCl}$ cotransporter: evidence for impaired routing mechanisms in Gitelman's syndrome. J Am Soc Nephrol. (2002) 13:1442-8. doi: 10.1097/01.ASN.0000017904.77985.03

28. Knepper MA, Brooks HL. Regulation of the sodium transporters NHE3, NKCC2 and NCC in the kidney. Curr Opin Nephrol Hypertens. (2001) 10:655-9. doi: 10.1097/00041552-20010900000017
29. Bobulescu IA, Moe OW. $\mathrm{Na}^{+} / \mathrm{H}^{+}$exchangers in renal regulation of acid-base balance. Semin Nephrol. (2006) 26:334-44. doi: 10.1016/j.semnephrol.2006.07.001

30. Fenton RA, Poulsen SB, de la Mora Chavez S, Soleimani M, Dominguez Rieg JA, Rieg T. Renal tubular NHE3 is required in the maintenance of water and sodium chloride homeostasis. Kidney Int. (2017) 92:397-414. doi: 10.1016/j.kint.2017.02.001

31. Elkjaer ML, Kwon TH, Wang W, Nielsen J, Knepper MA, Frøkiaer J, et al. Altered expression of renal NHE3, TSC, BSC-1, and ENaC subunits in potassium-depleted rats. Am J Physiol Renal Physiol. (2002) 283:F1376-88. doi: 10.1152/ajprenal.00186.2002

32. Khuri RN, Strieder WN, Giebisch G. Effects of flow rate and potassium intake on distal tubular potassium transfer. Am J Physiol. (1975) 228:1249-61. doi: 10.1152/ajplegacy.1975.228.4.1249

33. Malnic G, Berliner RW, Giebisch G. Flow dependence of $\mathrm{K}^{+}$secretion in cortical distal tubules of the rat. Am J Physiol. (1989) 256 (5 Pt 2):F932-41. doi: 10.1152/ajprenal.1989.256.5.F932

34. Wall SM, Verlander JW, Romero CA. The renal physiology of pendrin-positive intercalated cells. Physiol Rev. (2020) 100:1119-47. doi: 10.1152/physrev.00011.2019

35. Soleimani M, Barone S, Xu J, Shull GE, Siddiqui F, Zahedi K, et al. Double knockout of pendrin and $\mathrm{Na}-\mathrm{Cl}$ cotransporter (NCC) causes severe salt wasting, volume depletion, and renal failure. Proc Natl Acad Sci USA. (2012) 109:13368-73. doi: 10.1073/pnas.1202671109

36. Subramanya AR, Ellison DH. Distal convoluted tubule. Clin J Am Soc Nephrol. (2014) 9:2147-63. doi: 10.2215/CJN.05920613

37. Hebert SC. An ATP-regulated, inwardly rectifying potassium channel from rat kidney (ROMK). Kidney Int. (1995) 48:1010-6. doi: 10.1038/ki.1995.383

38. Lee WS, Hebert SC. ROMK inwardly rectifying ATP-sensitive K+ channel. I. Expression in rat distal nephron segments. Am J Physiol. (1995) 268 (6 Pt 2):F1124-31. doi: 10.1152/ajprenal.1995.268.6.F1124

39. Giebisch G. Renal potassium transport: mechanisms and regulation. Am J Physiol. (1998) 274:F817-33. doi: 10.1152/ajprenal.1998.274.5.F817

40. Welling PA, Ho K. A comprehensive guide to the ROMK potassium channel: form and function in health and disease. Am J Physiol Renal Physiol. (2009) 297:F849-63. doi: 10.1152/ajprenal.00181.2009

41. Pluznick JL, Sansom SC. BK channels in the kidney: role in $\mathrm{K}(+)$ secretion and localization of molecular components. Am J Physiol Renal Physiol. (2006) 291:F517-29. doi: 10.1152/ajprenal.00118.2006

42. Rodan AR, Huang CL. Distal potassium handling based on flow modulation of maxi-K channel activity. Curr Opin Nephrol Hypertens. (2009) 18:350-5. doi: 10.1097/MNH.0b013e32832c75d8

43. Kaissling B, Bachmann S, Kriz W. Structural adaptation of the distal convoluted tubule to prolonged furosemide treatment. Am J Physiol. (1985) 248 (3 Pt 2):F374-81. doi: 10.1152/ajprenal.1985.248.3.F374

44. Kaissling B, Stanton BA. Adaptation of distal tubule and collecting duct to increased sodium delivery. I. Ultrastructure. Am J Physiol. (1988) 255 (6 Pt 2):F1256-68. doi: 10.1152/ajprenal.1988.255.6.F1256

45. Loffing J, Vallon V, Loffing-Cueni D, Aregger F, Richter K, Pietri L, et al. Altered renal distal tubule structure and renal $\mathrm{Na}^{+}$and $\mathrm{Ca}^{2+}$ handling in a mouse model for Gitelman's syndrome. J Am Soc Nephrol. (2004) 15:2276-88. doi: 10.1097/01.ASN.0000138234.18569.63

46. Grimm PR, Lazo-Fernandez Y, Delpire E, Wall SM, Dorsey SG, Weinman EJ, et al. Integrated compensatory network is activated in the absence of NCC phosphorylation. J Clin Invest. (2015) 125:2136-50. doi: 10.1172/JCI78558

47. Seyberth HW, Schlingmann KP. Bartter- and Gitelman-like syndromes: saltlosing tubulopathies with loop or DCT defects. Pediatr Nephrol. (2011) 26:1789-802. doi: 10.1007/s00467-011-1871-4

48. Matsunoshita N, Nozu K, Shono A, Nozu Y, Fu XJ, Morisada N, et al. Differential diagnosis of Bartter syndrome, Gitelman syndrome, and pseudoBartter/Gitelman syndrome based on clinical characteristics. Genet Med. (2016) 18:180-8. doi: 10.1038/gim.2015.56

49. Frindt G, Palmer LG. Effects of dietary $\mathrm{K}^{+}$on cell-surface expression of renal ion channels and transporters. Am J Physiol Renal Physiol. (2010) 299:F890-7. doi: 10.1152/ajprenal.00323.2010

50. Wade JB, Liu J, Coleman R, Grimm PR, Delpire E, Welling PA. SPAKmediated NCC regulation in response to low-K+ diet. Am J Physiol Renal Physiol. (2015) 308:F923-31. doi: 10.1152/ajprenal.00388.2014 
51. Sonoda H, Lee BR, Park K-H, Nihalani D, Yoon J-H, Ikeda M, et al. miRNA profiling of urinary exosomes to assess the progression of acute kidney injury. Scientific Reports. (2019) 9:4692. doi: 10.1038/s41598-019-40747-8

52. Awdishu L, Tsunoda S, Pearlman M, Kokoy-Mondragon C, Ghassemian M, Naviaux RK, et al. Identification of maltase glucoamylase as a biomarker of acute kidney injury in patients with cirrhosis. Crit Care Res Pract. (2019) 2019:5912804. doi: 10.1155/2019/5912804

53. Khurana R, Ranches G, Schafferer S, Lukasser M, Rudnicki M, Mayer G, et al. Identification of urinary exosomal noncoding RNAs as novel biomarkers in chronic kidney disease. Rna. (2017) 23:142-52. doi: 10.1261/rna.058834.116

54. Wang B, Zhang A, Wang H, Klein JD, Tan L, Wang ZM, et al. miR26a limits muscle wasting and cardiac fibrosis through exosome-mediated microRNA transfer in chronic kidney disease. Theranostics. (2019) 9:1864-77. doi: 10.7150/thno. 29579

55. Zang J, Maxwell AP, Simpson DA, McKay GJ. Differential expression of urinary exosomal microRNAs miR-21-5p and miR-30b-5p in individuals with diabetic kidney disease. Sci Rep. (2019) 9:10900. doi: 10.1038/s41598-019-47504-x

56. Gebeshuber CA, Kornauth C, Dong L, Sierig R, Seibler J, Reiss M, et al. Focal segmental glomerulosclerosis is induced by microRNA-193a and its downregulation of WT1. Nat Med. (2013) 19:481-7. doi: 10.1038/n m.3142

57. Garcia-Vives E, Solé C, Moliné T, Vidal M, Agraz I, Ordi-Ros J, et al. The urinary exosomal miRNA expression profile is predictive of clinical response in lupus nephritis. Int J Mol Sci. (2020) 21:1372. doi: 10.3390/ijms21041372

58. Salih M, Fenton RA, Knipscheer J, Janssen JW, Vredenbregt-van den Berg MS, Jenster G, et al. An immunoassay for urinary extracellular vesicles. Am J Physiol Renal Physiol. (2016) 310:F796-801. doi: 10.1152/ajprenal.00463.2015

Conflict of Interest: The authors declare that the research was conducted in the absence of any commercial or financial relationships that could be construed as a potential conflict of interest.

Copyright (c) 2021 Sung, Chen, Lin, Lin, Lin, Yang and Lin. This is an open-access article distributed under the terms of the Creative Commons Attribution License (CC $B Y)$. The use, distribution or reproduction in other forums is permitted, provided the original author(s) and the copyright owner(s) are credited and that the original publication in this journal is cited, in accordance with accepted academic practice. No use, distribution or reproduction is permitted which does not comply with these terms. 